\title{
Fracture of elastic-brittle and elastic-plastic material in cantilever cyclic bending
}

\author{
Andrzej Kurek, Tadeusz Lagoda \\ Opole University of Technology, 45-271 Opole, 5 Mikolajcayka St., Poland \\ a.kurek@po.opole.pl,0000-0001-7316-1858 \\ t.lagoda@po.opole.pl,0000-0002-2815-331
}

\begin{abstract}
The paper analyses the fatigue tests on specimens made of $16 \mathrm{Mo} 3$ steel and 6082-T6 aluminium alloy performed under bending and tensile conditions. It has been shown that in the case of bending of the $16 \mathrm{Mo} 3$ steel specimen, in low cycle fatigue (LCF) range, the fatigue life increases with respect to the results obtained under tension-compression conditions. On the other hand, in the case of the aluminium specimen, the load condition practically does not affect the fatigue life. Microstructural analysis revealed almost homogeneous fatigue cracks in the $16 \mathrm{Mo} 3$ steel samples which are practically elastic-plastic. The analysed 6082-T6 aluminium alloy belongs to the group of materials characterized by elastic and brittle properties. In the case of pendulum bending in the obtained images, it is possible to notice the clear pits at an angle of about 45 degrees relative to the surface of the breakthrough. They penetrate the broken specimen to about $33 \%$. In the middle of the material, the bending plane is clearly visible, where the stress is constant and equals $0 \mathrm{MPa}$.
\end{abstract}

KEYWORDS. Tension-compression; Pendulum bending; Strain-life curves.

Citation: Kurek, A., Lagoda, T., Fracture Of Elastic-Brittle and Elastic-Plastic Material in Cantilever Cyclic Bending, Frattura ed Integrità Strutturale, 48 (2019) 42-49.

Received: 28.11 .2018

Accepted: 02.02.2019

Published: 01.04.2019

Copyright: (C) 2019 This is an open access article under the terms of the CC-BY 4.0, which permits unrestricted use, distribution, and reproduction in any medium, provided the original author and source are credited.

\section{INTRODUCTION}

$\mathrm{I}$ $\mathrm{n}$ most cases, as far as a fatigue life analysis is concerned, only normal or tangential stresses are mentioned. Generally, the origin of such stresses is not taken into account. Normal stress amplitude $\sigma_{a}$ may originate from tensioncompression, pendulum bending with a cantilever, three-point or four-point bending or rotary bending. Only in few studies, the differences in fatigue life resulting from a load condition [1 - 5] were noted. As a consequence, a different fatigue life corresponds to the same strain or tension amplitude. In the study [6] it has been shown that the change of a bending plain itself by the angle of $\pi / 2$ results in a change of fatigue life. Unfortunately no attempt was made to analyze this phenomenon in none of the cited studies. 
The analysis of the impact of various load conditions (tension-compression and cantilever pendulum bending) on a fatigue life is made in this study. This analysis is carried out based on the elastic-brittle material (aluminium 6082-T6) and the elastic-plastic material (steel 16Mo3). The impact of the load condition on a fatigue life and a fatigue breakthrough structure is compared.

\section{FATIGUE TESTING OF STEEL AND ALUMINIUM}

he tests of two types of materials were subjected to analysis. The representative of the elastic-brittle material is aluminium alloy 6082-T6 and the representative of the elastic-plastic material is $16 \mathrm{Mo} 3$ steel used mostly in the power industry. The Tab. 1 presents the designation of these materials according to various standards.

\begin{tabular}{cccccc}
\hline Material & DIN & ISO & PN & Werkstoff & EN \\
6082 & AlMgSi1 & AlSi1MgMn & PA4 & 3.2315 & 6082 \\
$16 \mathrm{Mo3}$ & $15 \mathrm{Mo3}$ & $16 \mathrm{Mo3}$ & $16 \mathrm{M}$ & 1.5415 & $16 \mathrm{Mo3}$ \\
\hline
\end{tabular}

Table 1: Material designations according to various standards (equivalents)

The chemical compositions are presented in Tab. 2, and the mechanical properties of the analyzed materials in the Tab. 3. The test results under the conditions of uniaxial tension-compression for respective materials: 6082-T6 [7-12] and 16Mo3 [13-15] are taken from the literature. The cyclic properties of the materials under analysis are presented in Tab. 4, where the tests under the cantilever bending conditions were carried out at the controlled moment amplitude for the aluminium alloy 6082-T6 and the controlled amplitude of total strain for both materials. These tests were performed at the MZGS100 test stands constructed by Achtelik which constitute the equipment of the Department of Mechanics and Machine Design at the Faculty of Mechanical Engineering of the Opole University of Technology. The first test stand is presented in Fig. 1a. This test stand has already been repeatedly used for various experimental tests.

\begin{tabular}{|c|c|c|c|c|c|c|c|}
\hline $\mathrm{Cu}$ & $\mathrm{Mg}$ & $\mathrm{Mn}$ & $\mathrm{Si}$ & $\mathrm{Fe}$ & $\mathrm{Zr}+\mathrm{Ti}$ & $\mathrm{Zn}$ & $\mathrm{Cr}$ \\
\hline$<0.1$ & $0.6 \div 1.2$ & $0.4 \div 1.0$ & $0.7 \div 1.3$ & $<0.5$ & $<0.1$ & $<0.2$ & $<0.25$ \\
\hline \multicolumn{8}{|c|}{ Steel $16 \mathrm{Mo} 3$ (in $\%$, Fe balance) } \\
\hline $\mathrm{C}$ & Мo & $\mathrm{Mn}$ & $\mathrm{Si}$ & $\mathrm{P}$ & S & $\mathrm{Ni}$ & $\mathrm{Cr}$ \\
\hline 0.18 & 0.325 & 0.55 & 0.29 & 0.019 & 0.010 & 0.04 & 0.06 \\
\hline
\end{tabular}

Table 2: Chemical compositions

\begin{tabular}{ccccc}
\hline Material & $\mathrm{R}_{\mathrm{p} 0,2, \mathrm{MPa}}$ & $\mathrm{R}_{\mathrm{m}}, \mathrm{MPa}$ & $\mathrm{A} \%$ & $\nu$ \\
6082-T6 & 365 & 385.2 & $27.2\left(\mathrm{~A}_{12,5}\right)$ & 0.32 \\
16Mo3 & 335 & 481 & $24\left(\mathrm{~A}_{5}\right)$ & 0.30 \\
\hline
\end{tabular}

Table 3: Basic mechanical properties

\begin{tabular}{cccccccc}
\hline Material & $\mathrm{K}, \mathrm{MPa}$ & $\mathrm{n}$ & $\mathrm{E}, \mathrm{GPa}$ & $\sigma_{\mathrm{f}, \mathrm{MPa}}^{\prime}$ & $\varepsilon_{\mathrm{f}}^{\prime}$ & $\mathrm{b}$ & $\mathrm{c}$ \\
6082-T6 & 526.1 & 0.0651 & 77 & 650.6 & 1.292 & -0.078 & -1.014 \\
$16 \mathrm{Mo3}$ & 1038 & 0.133 & 210 & 780.4 & 0.223 & -0.096 & -0.047 \\
\hline
\end{tabular}

Table 4: Cyclic properties

The second test stand (Fig. 1b) is a prototype test stand. "Diabolo" type samples were used in testing, the shape and dimensions of which are presented in Fig. 2. The tests in this case were carried out at the controlled lever inclination which is reflected (after rescaling) directly in the controlled amplitude of the total strain ( $\varepsilon_{\text {at }}$ ). A bending moment amplitude was also registered in the course of testing.

As fatigue life $\left(\mathrm{N}_{\text {exp }}\right)$ it was assumed that corresponding to a moment at which an inclination amplitude in the first case was increasing abruptly or in the other case, when the moment amplitude $\left(\mathrm{M}_{\mathrm{a}}\right)$ was dropping rapidly (by 15\%), what was 
reflected in a crack with a size of about $1 \mathrm{~mm}$ visible on the surface. The outline of moment routes at the controlled strain amplitude is presented in Fig. 3 for aluminium 6082, and in Fig. 4 for steel 16Mo3 at the set constant strain amplitude. In all tests, the ratio of asymmetry was $\mathrm{R}=-1$.

Smooth specimens with a constant cross-section of $10 \mathrm{~mm}$ diameter were used for tension-compression tests.

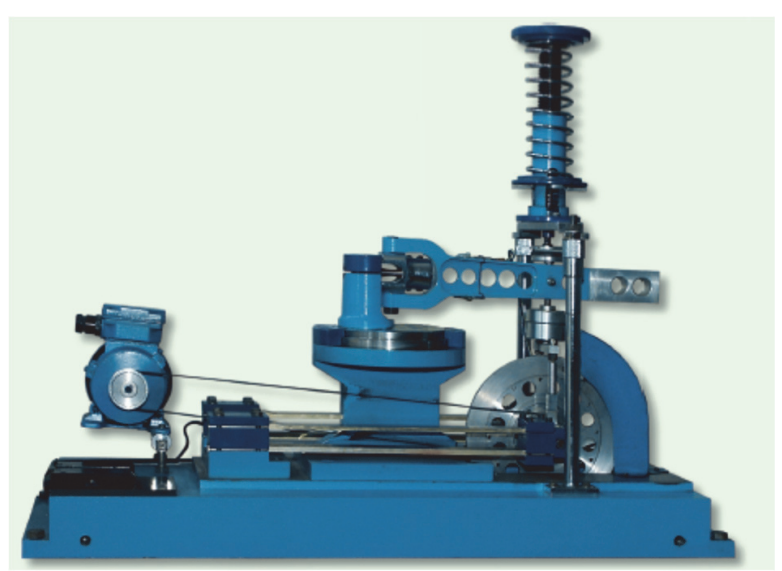

(a)

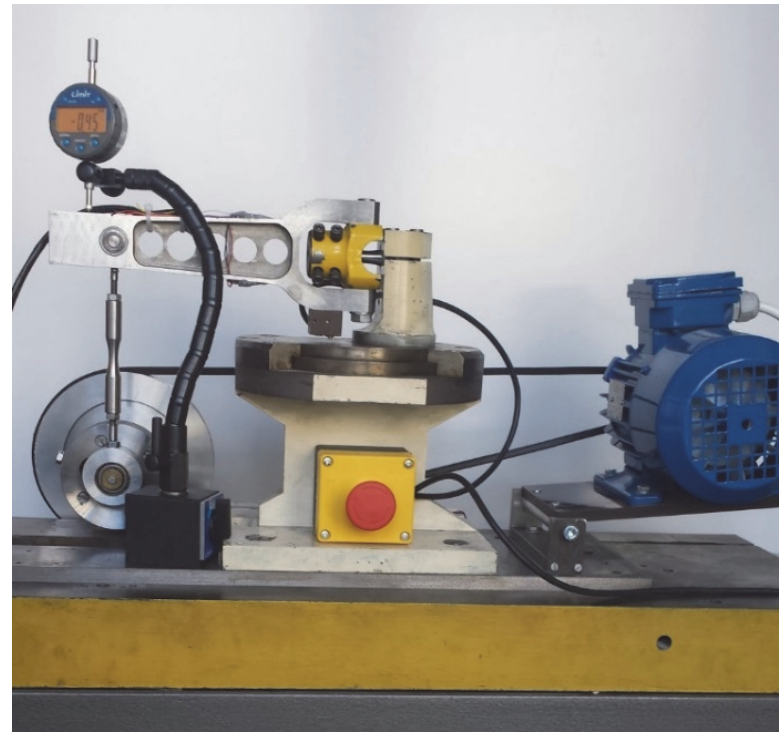

(b)

Figure 1: The test stand for fatigue testing under the cyclic bending conditions a) at the controlled moment, b) at the controlled strain

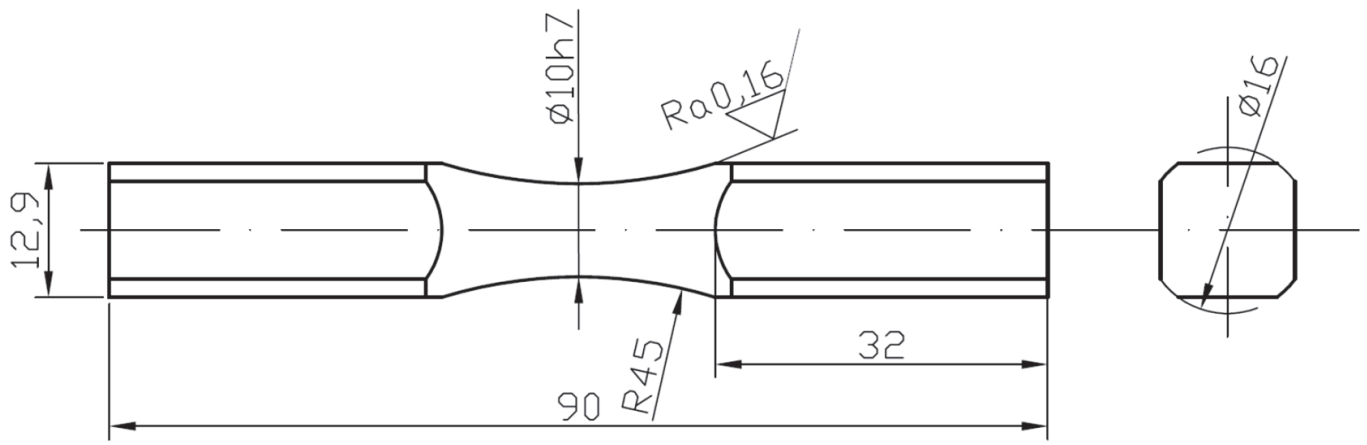

Figure 2: "Diabolo" type sample for bending fatigue testing

\section{THE COMPARISON OF FATIGUE LIFE IN TENSION-COMPRESSION AND PENDULUM BENDING}

he fatigue test results of the aluminium alloy 6082-T6 and the steel 16Mo3 are presented in Fig. 5 and Fig. 6. Apart from experimental points, the figures also present the Manson-Coffin-Basquin (MCB) characteristics in the form:

$$
\varepsilon_{a, t}=\varepsilon_{a, e}+\varepsilon_{a, p}=\frac{\sigma_{f}^{\prime}}{E}\left(2 N_{f}\right)^{b}+\varepsilon_{f}^{\prime}\left(2 N_{f}\right)^{c}
$$

where:

$\mathcal{E}_{a, t}$ - total strain amplitude expressed as the sum of the amplitudes of elastic strain $\varepsilon_{a, e}$ and plastic strain $\varepsilon_{a, p}$,

$2 \mathrm{~N}_{f}-$ the number of loading recurrences (semi-cycles),

$E$ - the Young's modulus,

$\sigma_{f}^{\prime}, b-$ fatigue life coefficient and exponent, 


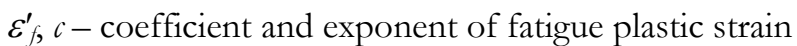

All the characteristics were determined in accordance with the ASTM standard [16].

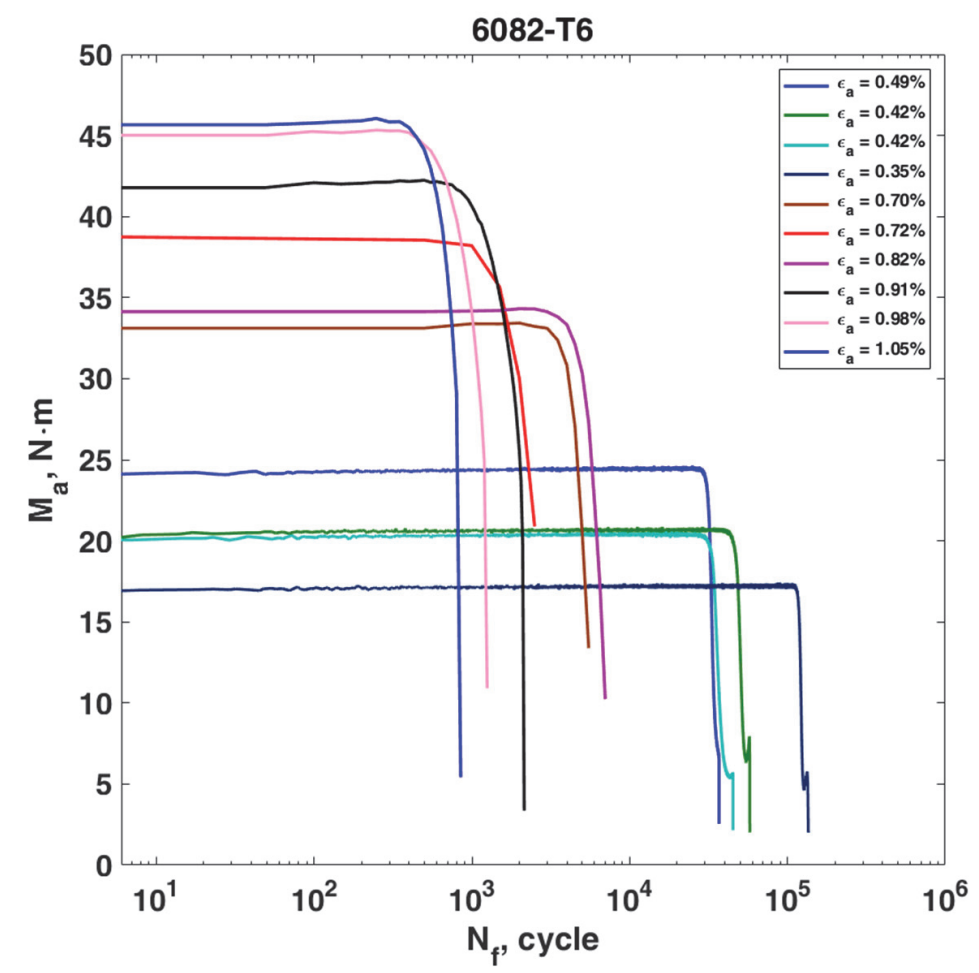

Figure 3: The change in the amplitude of bending moments in the function of cycle numbers for the aluminium alloy $6082-\mathrm{T} 6$.

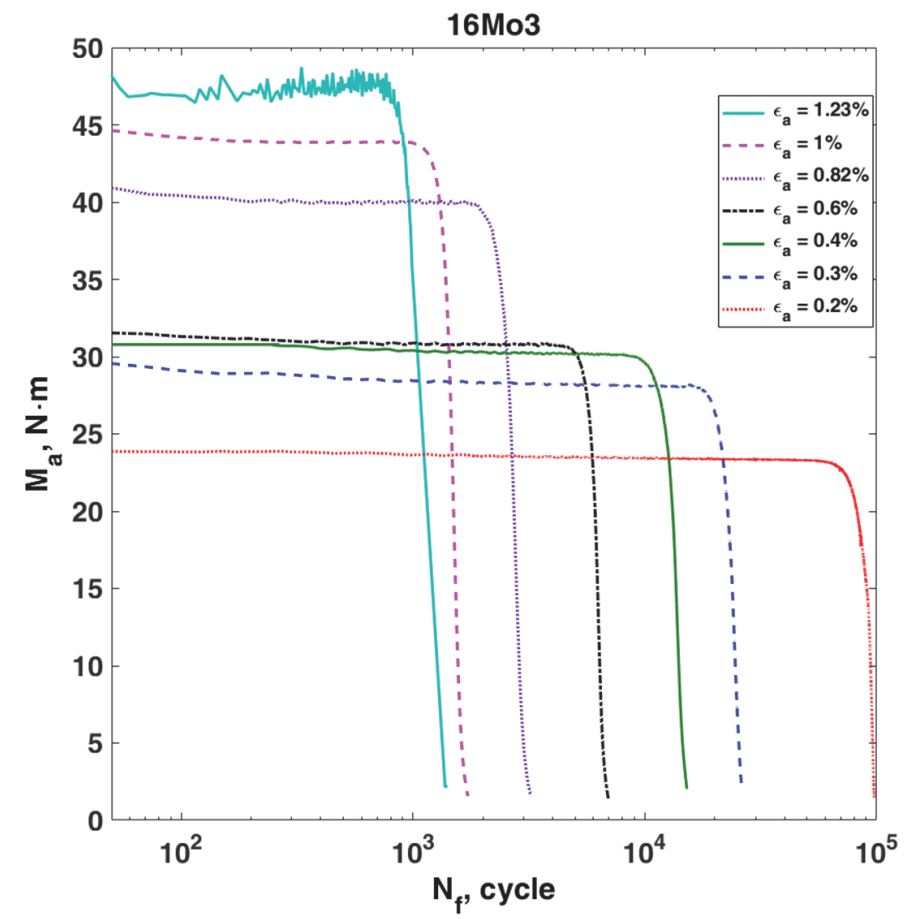

Figure 4: The change in the amplitude of bending moments in the function of cycle numbers for the steel $16 \mathrm{Mo}$. 
From the analysis of Fig. 3 and Fig. 4 it can be concluded that within a long period of time, the moment amplitudes are maintained at the constant level and then they drop abruptly. In case of the aluminium alloy the insignificant material cyclic strengthening can be observed, and in case of the analysed steel, cyclic weakening is also insignificant.

In case of the aluminium_6082-T6, these characteristics were determined based on the standard tests under the tensioncompression conditions and at cantilever pendulum bending, both at controlling of moment and strain. Whereas, in case of the steel $16 \mathrm{Mo} 3$, these characteristics were determined based on the standard tests under the tensioncompression conditions and at cantilever pendulum bending, controlled by strain. Note that the MCB strain characteristics in the event of bending may be determined only and exclusively with the pre-determined Ramberg-Osgood characteristic for tension-compression in the form of

$$
\epsilon_{a}=\frac{\sigma_{a}}{E}+\left(\frac{\sigma_{a}}{K^{\prime}}\right)^{1 / n^{\prime}}
$$

where:

K' - cyclic strengthening coefficient,

n'- cyclic strengthening exponent.

This characteristic is needed for determining elastic-plastic strains in the event of bending at the controlled moment and for dividing the strain amplitude into an elastic part and plastic part at bending and strain controlling [14].In case we have data from uniaxial tension-compression, Ramberg-Osgood equation constants (2), i.e. K' and n', we can separate an elastic and plastic part of the strain amplitude.

Fig. 5 indicates that in the event of the analysed aluminium alloy, the load type does not influence fatigue life. Thus, it is possible to determine a combined fatigue characteristic for three load conditions under analysis. This is completely different in the case of $16 \mathrm{Mo} 3$ steel (Fig. 6). Even when considering scatters of experimental data, characteristic for fatigue process, the differences in results of tension-compression and bending tests are significant. As mentioned in the introduction the impact of load conditions can be observed in the steels but not in aluminium alloys [19]. The biggest influence on this difference has the effect of stress gradient change in specimens which is different for those two materials. The gradient is linear for aluminium, which acts as a brittle material while in the case of elasto-plastic steel the gradient is nonlinear.

While analysing the results presented in this figure, we can notice that fatigue life for steel depends on the load type. This impact is greater as the strain amplitude increases. Whereas, as load decreases, this impact also decreases and it is not noticeable at the fatigue life level at approx. $10^{5}$ cycles.

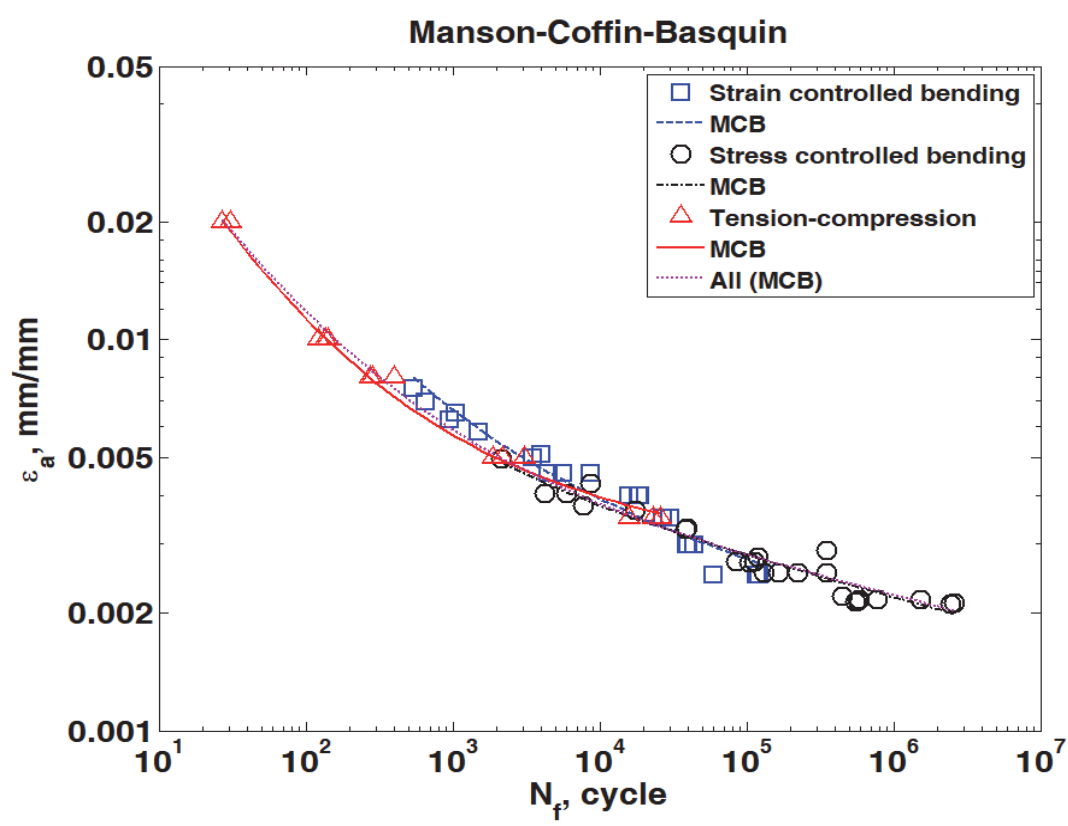

Figure 5: The strain characteristics of the aluminium alloy 6082-T6 for various load conditions 


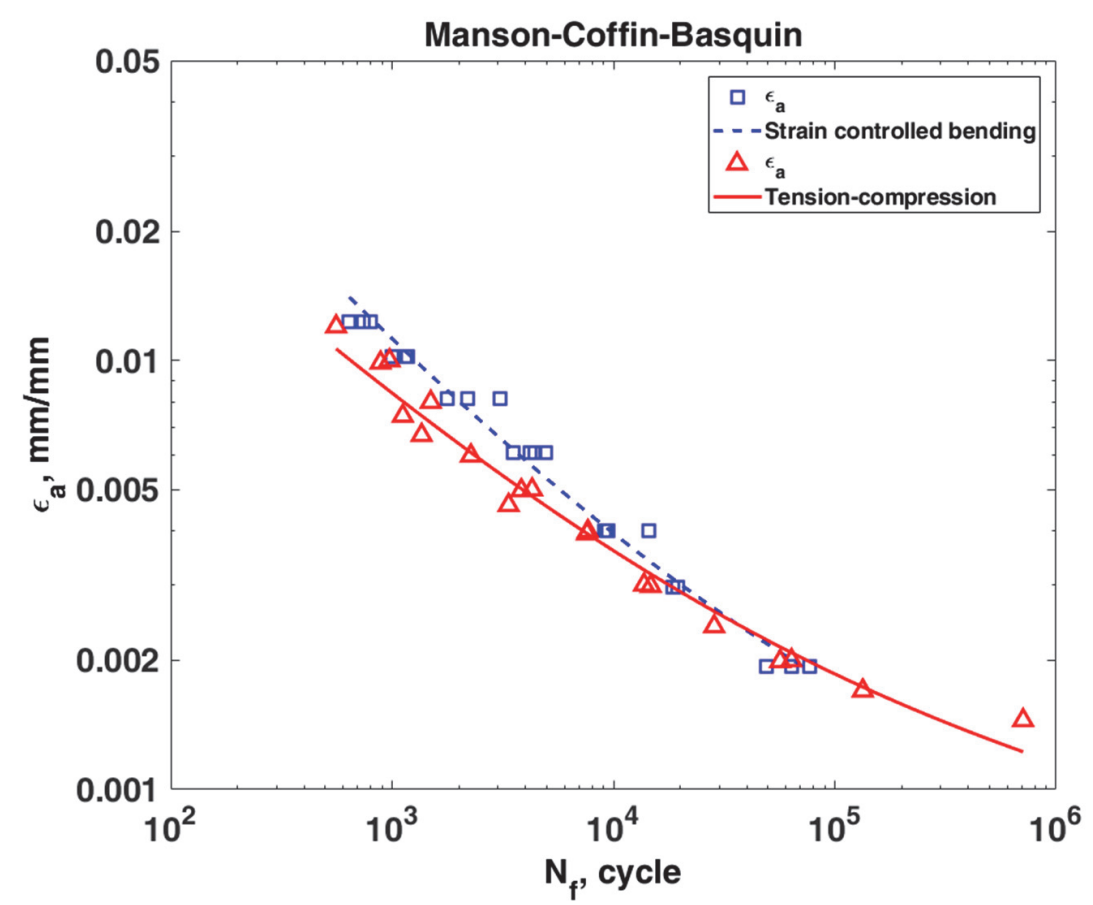

Figure 6: The strain characteristics of the steel 16Mo3 for various load conditions

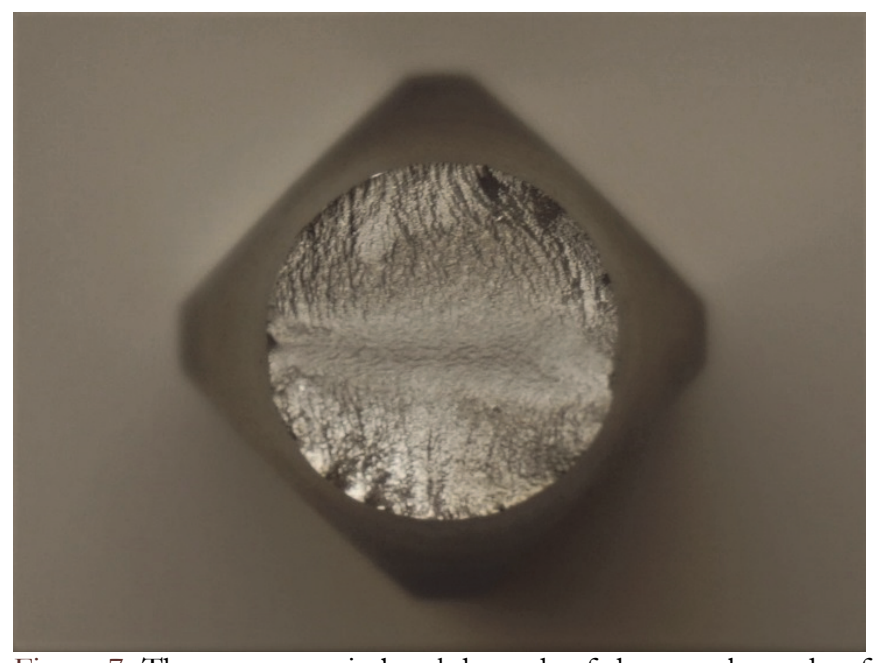

Figure 7: The macroscopic breakthrough of the sample made of steel 6082-T6 after testing under the pendulum bending conditions.

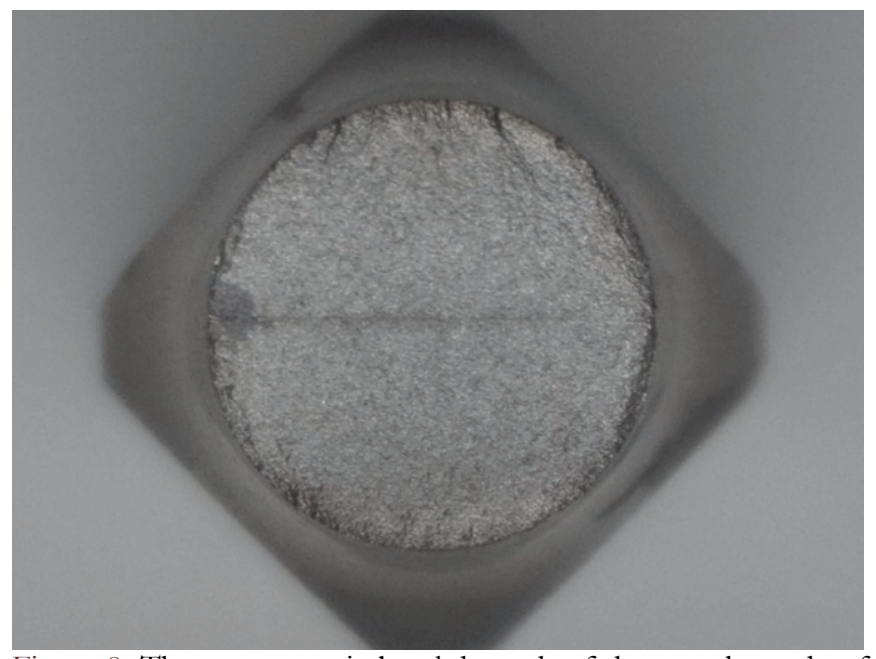

Figure 8: The macroscopic breakthrough of the sample made of steel $16 \mathrm{Mo} 3$ after testing under the pendulum bending conditions.

\section{THE ANALYSIS OF FATIGUE CRACKING AT PENDULUM BENDING}

A fter fatigue testing, under pendulum bending conditions, of samples made of two analysed materials, fatigue breakthroughs were analysed. This analysis proceeded along two paths. Firstly, fatigue scraps were reviewed in macroscopic and microscopic terms (Fig. 7 and Fig. 8). The analysis of the scrap obtained indicates that in the case of steel, a neutral plain passes through the geometrical half of the sample. In the point of maximum tensions, the traces of the initiation of fatigue cracks with fine pits can be observed.

In case of aluminium, a neutral plain also passes through, approximately, the geometrical centre of the sample, however, it is not as clear as in case of the analysed steel. Yet, in this case, there are clear pits oriented at the angle of $45^{\circ}$ towards the breakthrough surface. Such a cracking manner is described, inter alia, by Schijve in the study [17]. 
However, in case of the tests analysed, these pits are slightly of a different nature. The pits visible in Fig. 9 are in the shape of double shear lips and they run from the external surface to approximately $2 / 3$ along the line perpendicular to the bending plain. This cracking manner was anticipated and described in the study [18]. These pits are better visible in a microscopic photo. Such pits cannot be observed in the case of the tested steel, what is presented in Fig. 10.

Fig. 11 presents the outline of material cracking from the surface. In the first stage, cracking develops at the angle of $45^{\circ}$ and is determined by static tensions. In the second stage, cracking takes place at the angle of $90^{\circ}$ to the free plain and it is consistent with the normal tension direction. For the aluminium alloy analysed, the stage I dominates; while stage II dominates in the case of steel. This is confirmed by the fatigue breakthroughs of the analysed materials.

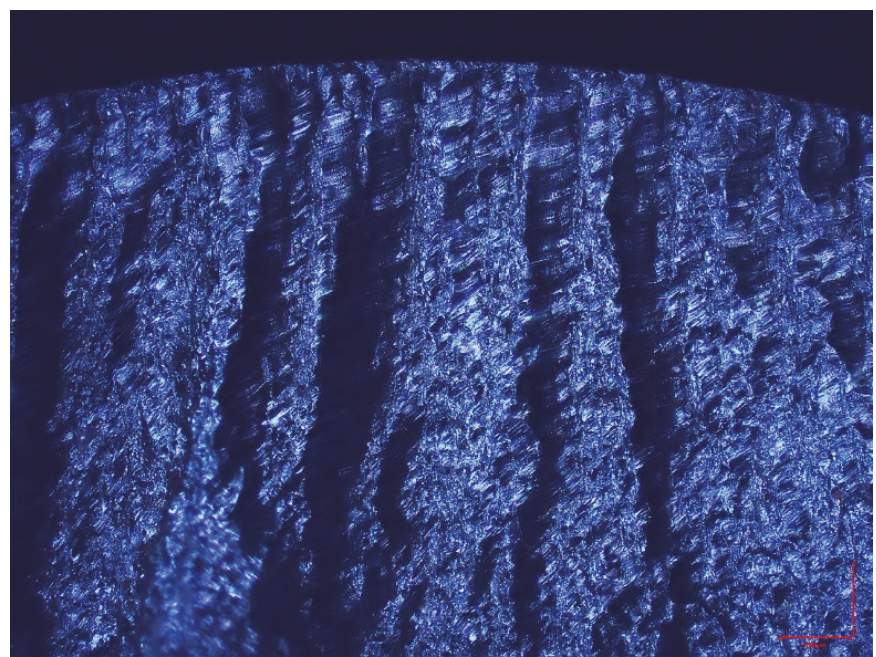

Figure 9: The microscopic breakthrough of the sample made of steel 6082-T6 after testing under the pendulum bending conditions.

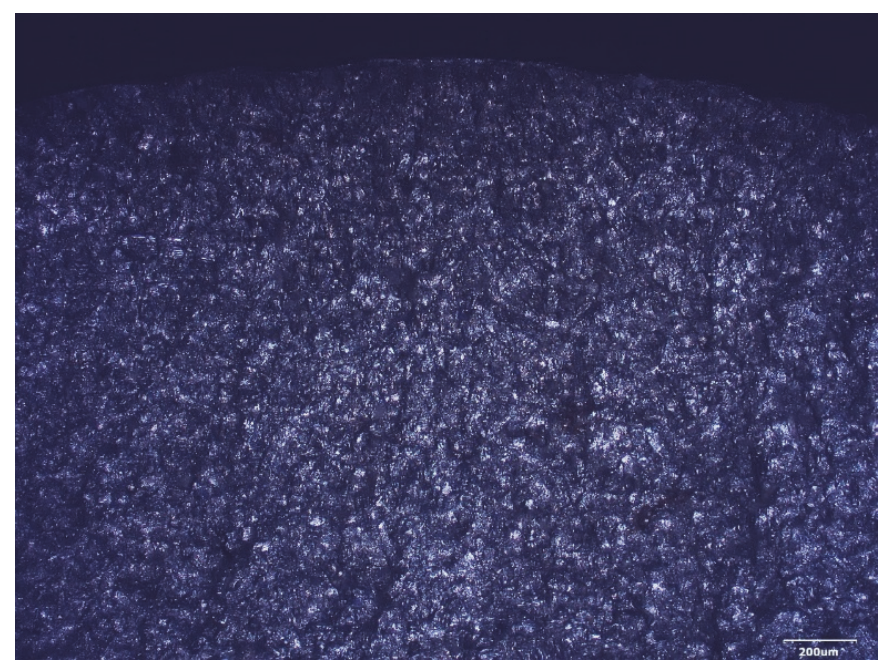

Figure 10: The microscopic breakthrough of the sample made of steel 16Mo3after testing under the pendulum bending conditions.

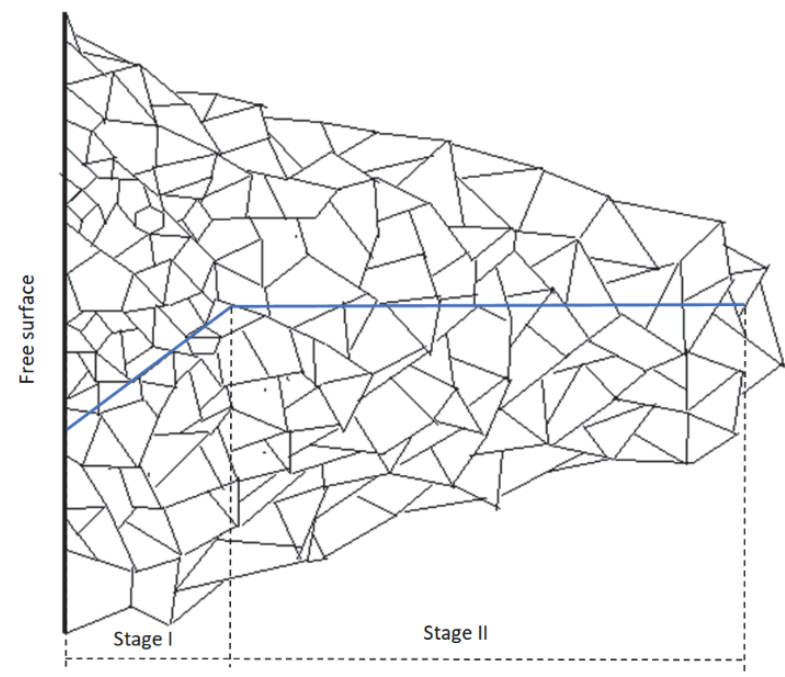

Figure 11: Cracking outlines divided into stages

\section{CONCLUSIONS}

1. Aluminium alloy 6082-T6 fatigue life is not dependent on load types and it may be described by one fatigue characteristic in the complete life range.

2. Steel 16Mo3 fatigue life depends on the load type. Within the scope of a low number of cycles, the strain characteristic for bending is higher than the characteristic for tension-compression. As the number of cycles increases towards destruction, it approaches the one determined for tension-compression. 
3. Fatigue scrap, during the pendulum bending of cantilevered samples made of aluminium 6082-T6, is characterized by double shear lips, and cracking is dependent on the stage I determined by tangential tension.

4. Fatigue scrap, during the pendulum bending of cantilevered samples made of steel $16 \mathrm{Mo} 3$, is characterized by an uniform structure, and the cracking process is dependent on the stage II determined by normal tension.

\section{REFERENCES}

[1] Troshchenko, V. (1996). High-Cycle Fatigue and Inelasticity of Metals, Multiaxial and Fatigue Design, ESIS 21, Mechanical Engineering Publications, London, pp. 335-358.

[2] Manson, S.S., Muralidharan, U. (1987). Fatigue life prediction in bending from axial fatigue information, Fatigue \& Fracture Engineering Materials \& Structures, 9(5), pp. 357-372.

[3] Hassan, T. and Liu Z. (2001). On the difference of fatigue strengths from rotating bending, four-point bending, and cantilever bending tests, Int. J. of Pressure and piping, 78, pp. 19-30.

[4] Megahed, M.M. (1990). Prediction of bending fatigue behaviour by the reference stress approach, Fatigue Fract. Engng. Mater. Struct., 13(4), pp. 361-374.

[5] Manson, S.S. (1965). Fatigue: A complex subject - some simple approximations, Experimental Mechanics, pp. 193226.

[6] Krzyżak, D., Kurek, M., Łagoda, T. Sówka, D. (2014). Influence of changes of the bending plane position on the fatigue life, Mat. -wiss. U. Werkstofftech., 45(11) pp.1018-1029.

[7] Kurek, M., Lagoda, T. (2017). Determination of the critical plane orientation depending on the fatigue curves for bending and torsion, Frattura ed Integrita Strutturale, 41, pp. 24-30.

[8] Carpinteri, A., Kurek, M., Lagoda, T., Vantadori, S. (2017). Estimation of fatigue life under multiaxial loading by varying the critical plane orientation, Int. J. Fatigue, 100, pp. 512-520.

[9] Ronchei, C., Carpinteri, A., Fortese, G., Spagnoli, A., Vantadori, S., Kurek, M., Lagoda, T. (2015). Life estimation by varying the critical plane orientation in the modified Caripnteri-Spagnoli criterion, Frattura ed Integrita Strutturale, 34, pp. 74-79.

[10] Kurek M., Łagoda T., Vantadori S. (2015). Estimation of fatigue life of selected construction materials under cyclic loading, Fracture and Structural Integrity, 33, pp. 302-308.

[11] Karolczuk, A., Kurek, M., Lagoda, T. (2015). Fatigue life of aluminium alloy 6082 T6 under constant and variable amplitude bending with torsion, J. of Theoretical and Applied Mechanics, 53(2), pp. 421-430.

[12] Niesłony, A., Lagoda, T., Walat, K., Kurek, M. (2014). Multiaxial fatigue behaviour of AA6068 and AA2017A aluminium alloys under in-phase bending with torsion loading condition, Mat.-wiss. U. Werkstofftech., 45(10), pp. 947-952

[13] Boller, C., Seeger, T. (1987). Materials Data for Cyclic Loading; Part B, Materials Science Monographs, 42D, Elsevier.

[14] Kulesa, A., Kurek, A., Lagoda, T., Achtelik, H., Kluger, K. (2016). Low cycle of steel in strain controlled cyclic bending, Acta Mechanica et Automatica, 10, pp. 62-65.

[15] Baumel Jr, A., Seeger, T. (1990). Materials Data for Cyclic Loading; Suplement 1, Materials Science Monographs, 61, Elsevier.

[16] ASTM E 1049-85, (1999). Standard practice for statistical analysis of linearized stress-life (S-N) and strain-life $(\varepsilon-N)$ fatigue data, in: Annual Book of ASTM Standards, 03.01, Philadelphia, pp. 614-620.

[17] Schijve, J. (2003). Fatigue of structures and materials in the $20^{\text {th }}$ century and the state of the art, Int. J. Fatigue, 25, pp. 679-702.

[18] Araujo de Oliveria, J., Kowal, J., Gungor, S., Fitzpatrick, M.E. (2015). Determination of normal and shear residual stresses from fracture surface mismatch, Materials and Design, 83, pp. 176-184.

[19] Kurek, A., Koziarska, J., \& Lagoda, T. (2018). Strain characteristics of non-ferrous metals obtained on the basic of different loads. Paper presented at the MATEC Web of Conferences, 165 doi:10.1051/matecconf/201816515005 . 